Journal of Construction Innovation: Information, Process, Management,

Volume 12 issue 2 https://doi.org/10.1108/14714171211215921

(c) Emerald Group Publishing Limited 2012

\title{
Evolution of large-scale Industrialisation and Service - Innovation in Japanese Prefabrication Industry
}

\begin{abstract}
Purpose - The Japanese prefabrication industry not only has automated its processes to a high extent, but it also innovates due to the fact that it delivers buildings of outstanding quality accompanied by a multitude of services. In order to explore and specify the concepts and parameters that have driven this industry, Japan's prefabrication industry, its cultural, economic and technological surrounding, as well as the applied processes, technologies and economic strategies, have to be illustrated and analyzed. The proposed research aim was to identify, describe and analyse these concepts and their related parameters, as well as to recognize the most influential drivers for the future, that provide an indication into which direction the industry could evolve.
\end{abstract}

Research Methodology - Being aware that literature does not provide relevant information and data, which would allow the authors to explore concepts and parameters explaining the success of the Japanese prefabrication industry, the authors performed field surveys, visited factories, $R \& D$ centres and sales points of all major Japanese prefabrication companies. In some cases authors also interviewed general managers, researchers and developers, and academicians at Japanese universities. Based on an extensive literature review in the area of product development, production technology, modularisation, mass customisation, and innovation, the authors qualitatively and quantitatively analysed all major prefabrication companies according to a fixed scheme. 
Findings - The concepts and parameters identified and analyzed in this paper, demonstrate that the Japanese prefabrication industry, which is leading in large-scale industrialization, nowadays focuses towards services that are related to the building's utilization phase, rather than delivering products. By involving customers it enhances the companies' customer relations, creating thus competitive advantages.

Originality/ value - Overall the paper shows that Japanese prefabrication industry rather acts like a "production industry" than a "construction industry". Similar to many other high-tech industries, Japan's prefabrication industry incorporates latest product and process technologies and combines automation, products and services into complex value-capturing systems.

Keywords: Building Production, Automation in Construction, Product and Service Innovation, Mass Customization, Japanese Prefabrication Industry

Category: Research/ Case Study

\section{Introduction}

Prefabrication holds a considerable share in the housing market in many European countries, such as Germany (15\%), Austria (up to 33\%), France (5\%), Spain (5\%) and the Scandinavian Countries. In Germany, currently about 20,000 prefabricated houses are delivered per year by companies as Bien-Zenker AG (580 houses/ year), Huf Haus GmbH (450 houses/ year), Weber Haus GmbH (600 houses/ year) and Kampa House GmbH (1,086 houses/ year). The advantage of buying prefabricated buildings is the low price compared to conventionally built buildings and the relatively rapid delivery (about six days period of delivery). However, the European prefabrication industry cannot really be considered industrialized. According to classical theory (e.g. Henry Ford's Mass Production) as well as modern concepts (e.g. flexible manufacturing, mass customization), industrialization implies that large scales of products were produced using latest production technology, automation, robotics, Information and Communication Technology (ICT), in order to deliver high quality products with reasonable costs. In Europe, no prefabrication company has yet reached the critical mass of an annual production, which would allow for investment in efficient processes and automation. It rather seems that conventional construction processes have been shifted to the factory and combined with elements of shop floor production. Furthermore, prefabrication in Europe has predominantly found its niche in the low cost market, which doesn't allow for product or service innovation. Unlike Japanese prefabricated buildings, the choices available to European customers to individualize those houses are rather low.

In Japan, the prefabrication industry mainly deals with middle to high-end market (Matsumura, 2007; Linner, 2007), for which it delivers highly customized and reliable products that are equipped with the latest technology available and accompanied by a variety of services. Above all, prefab houses are well known for being earthquake resistant. Various maintenance models guarantee the building's functionality for at least thirty years, and some companies offer even sixty years of service. Prefabrication companies altogether build about 150,000 housing units 
per annum. The following can be considered as a comparison: In 2008, the same amount of building permissions in private housing in Germany were issued both in conventional and prefabricated construction. Already in the nineteen-seventies, Sekisui Heim's legendary M1 reached an annual production volume of more than 3,000 buildings. A high annual production rate on a steady level allowed the investment in component systems, expensive manufacturing technology (e.g. production lines, automation, and robotics, advanced logistic systems) and extended customer services, which are labelling the uniqueness and strength of the Japanese prefabrication industry today. Moreover, the productivity of this industry has become so high, depending on the capacity utilization, that three to four customized buildings per employee can be realized annually (Sekisui Heim, 2008; Sekisui House, 2008). Japan's housing industry is amongst the strongest industries worldwide. However, it has undergone a steady change and decline since the 1990's. The maximum production peak was reached in 1994 with 573,173 newly constructed housing units. In 2000, about 450,000 units were constructed and in 2009 the construction went down to just 318,000 units. During peak times, the percentage of prefabricated houses, which were entirely prefabricated, was about 18 to $19 \%$. Today's quota has decreased to just 13 to 15\%, depending on the region (Sekisui Heim, 2010; Toyota Home, 2010). However, also in conventional construction, a high amount of prefabricated elements were used, which increases the actual percentage of prefabrication in the whole building industry, although it is difficult to give numbers. The prefabrication of entire buildings can be broken down into about $80 \%$ steel-based building kits, $15 \%$ wood-based building kits and 5\% concrete-based building kits.

\begin{tabular}{|l|l|l|l|l|}
\hline & Sekisui House & Daiwa House & Sekisui Heim & Toyota Home \\
\hline Units per year & $78,275(1994)$ & $44,500(2007)$ & $34,560(1997)$ & $5,024(2006)$ \\
\hline
\end{tabular}

Table 1: Maximum production peaks in housing of main players of the prefabrication industry.

Source: Yearly financial reports of Sekisui House, Daiwa House, Sekisui Heim and Toyota Home*

Sekisui House, which remains the main player in Japan's prefabrication industry, reached its peak in 1994 with a production of 78,275 housing units. At this time, Sekisui's quota of the total building construction market was 5,3\%. Both Sekisui House and Daiwa House, the second largest player in Japan's prefabrication industry, tried to encounter the decline in the market by going into a developer position. Houses and apartments were developed, planned and constructed in order to rent them out later. These houses and apartments are also based on mass

* Sekisui House: http://www.sekisuihouse.co.jp/ [Accessed 05 September 2011]

Daiwa House: http://www.daiwahouse.co.jp [Accessed 05 September 2011]

Sekishui Heim: http://www.sekisui.co.jp/ [Accessed 05 September 2011]

Toyota Home: http://www.toyotahome.co.jp/ [Accessed 05 September 2011] 
customisable housing kits and ensure that the capacities of expensive automated production facilities are utilised to a maximum.

\begin{tabular}{|l|c|c|c|c|}
\hline & Sekisui House & Daiwa House & Sekisui Heim & Toyota Home \\
\hline $\begin{array}{l}\text { Detached Houses } \\
\text { (sold to customers) }\end{array}$ & 17,389 & 8,586 & 10,300 & 4,302 \\
\hline $\begin{array}{l}\text { Apartment Houses } \\
\text { (sold to customers) }\end{array}$ & 5,699 & 3,511 & 4,250 & \\
\hline $\begin{array}{l}\text { Houses and Apartment } \\
\text { Units } \\
\text { (built and rent) }\end{array}$ & 32,000 & 29,021 & & \\
\hline $\begin{array}{l}\text { Houses sold with } \\
\text { other brand names } \\
\text { (Subdivisions) }\end{array}$ & 1,729 & & $\mathbf{1 4 , 5 5 0}$ & $\mathbf{4 , 3 0 2}$ \\
\hline Total & $\mathbf{5 5 , 0 8 8}$ & $\mathbf{4 2 , 8 4 7}$ & & \\
\hline
\end{tabular}

Table 2: Housing production of main players in 2009.

Source: Yearly financial reports of Sekisui House, Daiwa House, Sekisui Heim and Toyota Home *

To address the decrease in demand and to build up new ways of value creation, all main players are focusing more and more on the building's utilization phase, building performance and advanced Building Information Modelling (BIM), in order to manage the building's life-cycle and provision of more and more services accompanying the hard physical product.

\section{Research Question}

Comparing the European and the Japanese prefabrication market using the aforementioned facts and figures, it can be concluded that prefabrication in Japan is much more industrialized. This means that companies have higher production volumes, along with standardized processes, justin-time, automation and flow line-like production, (together with human work activity), in all factories of the four biggest prefabrication companies. Despite this high degree of industrialization, prefabricated buildings are considered as the most customized, reliable, technology-equipped and properly designed buildings in Japan. Above all, Japanese

* Sekisui House: http://www.sekisuihouse.co.jp/ [Accessed 05 September 2011]

Daiwa House: http://www.daiwahouse.co.jp [Accessed 05 September 2011]

Sekishui Heim: http://www.sekisui.co.jp/ [Accessed 05 September 2011]

Toyota Home: http://www.toyotahome.co.jp/ [Accessed 05 September 2011] 
prefabrication companies have managed to bundle a variety of customer services to their buildings. Thus, Japanese prefabrication industry is not only to a high extend industrialized but at the same time innovative, as it delivers buildings of outstanding quality (customized, earth quake resistant, properly designed, reliable, equipped with the latest technology). Now this industry even starts to create a completely new business services. In order to explore and specify the concepts and parameters that have driven this industry its' cultural, economic and technological surrounding as well as applied processes, technologies and economic strategies have to be described and analyzed. As in many success stories of complex socio-technical systems (Fujimoto, 1999), we assume that the success of Japan's prefabrication industry today, was also based on a complex relation of concepts and parameters, that evolved out of historic and cultural developments. The research aim is to identify, describe and justify these concepts and related parameters, and to recognize the most likely and influential drivers for the future, that provide an indication in which direction the industry could evolve.

\section{Research Methodology}

Large scale industrialization and automation is a rare phenomenon that was not only discussed theoretically, but also applied in real life. The Moma Catalogue (Bergdoll and Christensen, 2008), accompanying the 2008 exhibition "Home Delivery", is one of the most recent collections of concepts, projects and real-life examples of prefabricated buildings. It clearly revealed that most ideas about prefabrication remain abstract concepts (Archigram, Metastadt), others are only built once or a few times, and only a few have reached a reasonable production number (e.g. some systems of Jean Prove). Similarly, none of the building systems mentioned, analysed and discussed in the book "New Perspective in Industrialization in Construction - A State-of-the-Art Report”, published in 2010 and co-authored by experts from CIB's TG 57 (Girmscheid and Scheublin, 2010), has reached an extent of production that is comparable to the mentioned Japanese systems. Comparable amounts, or a comparable degree, of automation has not been achieved even in the prefabrication of concrete elements for the civil engineering and infrastructure sector (Bock and Linner, 2010; Girmscheid, 2010). Furthermore, in the area of open building systems, most systems discussed are conceptual or experimental (Habraken, 2000; Kendall and Teicher, 2000). As mentioned in literature, you cannot extract guidelines that determine success, especially when dealing with concepts or projects, which are applied in larger scales. Due to cultural barriers and limited access of foreigners to the Japanese society, economy and technology, only a few international publications about the Japanese prefabrication market have been proposed. In (Wimmer, 2009), the author visited Sekisui House and mainly discusses the resource efficiency of the Japanese prefabrication industry. In (Johnson, 2008), economic concepts of the Japanese prefabrication market are discussed and comparisons to the market of the United Kingdom are made. Nevertheless, the author does not mention in detail the production technology and the service aspects. Similarly, (Andersson, et al., 2010) deals with the application of building information modelling in the Japanese prefabrication industry, without mentioning the context in which this happens. In general, researchers of Japanese prefabrication companies do not easily publish about their own technologies. One of the rare publications about the production system (Furuse and Katano, 2006), was issued in the International Symposium on Automation and Robotics in Construction 
held in Tokyo. Further books, brochures and websites, directly from the Japanese prefabrication companies, are predominantly written in Japanese language and do not reveal details about strategies and technologies. Being aware of the situation that literature does not provide relevant information and data, which would allow the authors to explore concepts and parameters in order to explain the success of Japanese prefabrication, the authors started a field survey. Visits to factories, R\&D centres and sales points of all four mentioned prefabrication companies, were conducted. The authors also interviewed general managers, researchers and developers (Sekisui House, 2008 and 2009; Daiwa House, 2008; Sekisui Heim, 2008 and 2010; Toyota Home, 2008, 2009 and 2010). Furthermore, they interviewed researchers at the University of Tokyo and the Kyushu University, which were familiar with the subject. Based on extensive literature review in the area of product development, production technology, modularization, mass customization and innovation (Baldwin and Clark, 2000; Ohno, 1988; Maraghy and Wiendahl, 2009; Piller, 2006; Chesbrough, 2011; Forza and Salvador, 2007), the authors qualitatively and quantitatively analyzed all four mentioned companies during their field survey, concerning the designed scheme to reflect the value chain:

1. Evolution of the company and the companies systems

2. Design Aspects: product structure, modularization, design for production

3. Degree of customer integration

4. Supply chain management

5. Off-Site Process: Automation and production technology, factory layouts

6. On-Site Process: completion process on site

7. Life-cycle management and customer relationship

8. Service Innovation

According to their analysis, it was realised that Sekisui House and Daiwa House have a high production outcome, but compared to Sekisui Heim and Toyota Home, they have a lower degree of automation and work tasks done in the factory. Toyota Home performs about $85 \%$ of all works in the factory, (highest degree of prefabrication), but hardly ever produced more than 5,000 houses per annum. The Sekisui Heim company was the most interesting to the authors. Sekisui Heim has applied a flow production on the production line which was very close to automotive industry, regarding organisation and appearance. Sekisui Heim has a medium sized production outcome and a prefabrication degree of about $80 \%$. In this paper, the authors therefore focus on Sekisui Heim and identify, describe and analyse parameters that are relevant for efficient large scale industrialization. The other companies will be analysed in further papers. Comparative analysis of all four companies mentioned above will be also realized in further papers.

The remainder of the paper is structured as follows: First, an analysis of how the historic and cultural development led to the evolution of large-scale industrialization is presented, by crosslinking to Sekisui House and Toyota Home, as all major companies have influenced continuously each other. Secondly, the strategies, processes and technologies deployed at Sekisui Heim today are depicted. Thirdly, it is shown that customer services play an important role in Sekisui Heim's success and that the proposed analysis has revealed the fact that more service innovation is under development in the R\&D centres of the prefabrication companies. 
Finally, the importance of this development for a changing housing industry is discussed. A summarization of the findings concludes the proposed paper.

\section{Historic and Cultural Development: the Evolution of Prefabrication in Japan}

Japanese prefabrication and construction automation are often presented as genius and advanced strategies, that were developed by companies, innovators and governmental institutions in the 1970 's-1990's. In the same way, it is also discussed why large-scale industrialization and automated construction has been applied successfully only in Japan, and why innovators in other locations and environments cannot manage to build up similar structures, although their technologies, processes and strategies might be even more advanced. One helpful contribution to these discussions and questions can be given by an evolutionary view on the subject. Just as Takahiro Fujimoto describes today's performance of the Toyota Production System as a consequence of evolution (Fujimoto, 1999), the existence of large-scale and highly automated prefabrication of individual buildings in the Japanese housing industry can be described as the outcome of a long-term learning and development process. Japan's advanced prefabrication industry was formed by a combination of continuous incremental and disruptive innovations and a unique socio-economic and socio-cultural environment (desire for new, fast changing markets, earthquakes, reduced human resources, service attitude) stepwise over time. Traditionally, organizational culture in Japan is based on collective, non-hierarchical and informal decision-making ("ringi seido"), bringing information from customers and production directly to management and product design, allowing thus the company's organization to evolve and adapt over time. Over centuries, prefabrication has been deeply connected to Japanese architectural culture. Traditional Japanese timber construction can be considered an early example of high-level prefabrication in the building industry. Additionally, Japanese tradition is closely related to a strong favour for order, standardisation and systematisation. An important activator for early prefabrication was found in the famous Ken, a 1:2 relation proportion and measurement system. Furthermore, tatami mats - the traditional Japanese floor finishing principally follows strict grids and order systems. Having usually an edge length of $85 \mathrm{~cm}$ x 170 $\mathrm{cm}$, tatami mats can be combined in a lot of variations in order to shape the room's dimension, which is always designed in an exact number of mats - a necessity since the mats had continuously been changed between the rooms, according to their current usage. Two layouts became common: The Syugijiki-Layout always has two tatami mats in its centre, surrounded by a number of additional mats, whereas the Fusyugijiki-Layout places several mats parallel in a strict orientation. Today, it is still common, that a room size is expressed with the number of Tatami mats instead of square meters. Contemporary Japanese architects are at the same time familiar with these rules and measurement systems and standardization often results in a particular multilevel grid, which can be found not only in the building's foot print but as an underlying rhythm also in its elevations, as well as in its decorative built-in parts, such as religious corners, wardrobes or shoji-screens (traditional Japanese sliding doors), allowing an easy combination or reconfiguration of rooms (Figure 1). Even some urban master plans follow these incremental measures, since each building unit is related to a multiplication of Tatami 
mats. This favour for standardization and measurement systems generated a supportive environment for prefabrication.

\section{Sekisui Heim M1: Design for Production}

In 1968, Kazuhiko Ono developed, as part of his doctoral thesis at the Tokyo University, the legendary M1 system of Sekisui Heim. This three-dimensional modular kit was famous for its genius simplicity. It could reduce the complexity in order to allow industrial line-based production. The M1 was a prototype for merging multiple qualities, design and production aspects. The "units" based on steel frames perfectly suited to the industrial production and low number of components could generate a variety of possible solutions for the customer. In the 1970's, the M1 reached an annual and steady production of more than 3,000 units per annum allowing the investment in advanced automation. (Figure 2)

\section{From Japan's Traditional Organizational Culture towards Toyota Home}

A further milestone in the evolution of mass customized building production has been set up by Toyota and the application of the legendary Toyota Production System (TPS) to manufacturing of space units. After the Second World War, the Toyota Motor Corporation was initially seeking methods, to increase its productivity rapidly. During several visits in the factories of Ford and General Motors, managers of Toyota realized that a production concept based on mass and variation production would never have great success, especially not in Japan (Ohno, 1988). According to Toyota, the ability of a fast adjustment to the frequent change of market needs in Japan was essential for a new production system. Under these circumstances, Toyota started to invent its own marked-based production system, tailored on Japanese requirements: The Toyota Production System. The revolution was the extension of conventional material and information flows ("Push Production") into a new concept, based on current demands ("Pull Production"). In a pulling production, the assembly line delivers only products, which were demanded to avoid stocks and overproduction. An integrated communication system called "Kanban" was developed to support the new information and material flow. The important aspect is that the Kanban information chain is started by the demand of a customer for a specific product with a specific configuration. Thus, the factory's output is “pulled” by customers, instead of formerly "pushing” when the output has been defined by the factory management and storage capacities. The complete synchronization of production and customer demands requires also a strict synchronization between factory and suppliers, since previous work steps are only being executed on the request of subsequent steps, just-in-time and just-in-sequence. Another achievement of Taichi Ohno was the application of a "zero-wastage-policy". Since Japan received only little economical support after the Second World War, it was required to find an efficient way to work with existing resources. Therefore, Ohno disclosed seven major waste producers in his concept. The most common waste-producer identified was over-production: a product is being delivered without a customer's demand. Finally, in the 1970's, Toyota develop its housing business with Toyota Home and started to produce prefabricated houses, transferring 
the Toyota Production System from its automotive section to the industrialized and production line-based manufacturing of buildings. During the following decades, all other main players of the prefabrication industry followed this newly set trend installing the basic ideas of TPS in their plants, products and organizations.

\section{Introduction of Enterprise Resource Planning Systems by Sekisui Heim}

After the successful application of the Toyota Production System (TPS) in the fields of building manufacturing, Sekisui Heim followed Toyota and adapted and refined TPS, as well. However, in the 1980's, Sekisui came up with another essential innovation: the parent company Sekisui Chemical developed an innovative computer-based Enterprise Resource Planning (ERP) system, for controlling the production and logistic flow. This ERP system was subsequently transferred to the Sekisui Chemical's subsections. In the housing section, this ERP system laid the foundation for HAPPS (Heim Automated Parts Pickup System). The system translates floor plans and design requirements of architects and customers directly into production plans and data, needed to operate automated production. Today, it can also be used to develop new platforms, components and solution spaces. It assures a complete communication between suppliers, work steps on different sections, timing and feeding of the 400-metre-assembly-line. Therefore, HAPPS chooses for one building approximately 30,000 parts out of 300,000 listed items and arranges them just-in-time and just-in-sequence for production.

\section{Analysis of currently applied Processes and Technologies}

The following explains the basic strategies of Japanese prefabrication industry. Sekisui House and Daiwa House use light steel frame panels, allowing tremendous scale effects in automated production, as well as a compact transport to the construction site with less logistical efforts. In contrast to that, Sekisui Heim and Toyota Home have based their strategy on steel frame cubicles used as a chassis on a conveyor belt. This allows a house to be completed within the factory, to a percentage reaching $85 \%$. In this proposed paper, the basic industrialization strategies by a case study of Sekisui Heim's Unit method are explained.

\begin{tabular}{|l|l|}
\hline Annual Production & 14,550 Houses (2009) \\
\hline Product Structure & $\begin{array}{l}\text { 3-dimensional Space Frames, Steel/Wood (Unit } \\
\text { Method) }\end{array}$ \\
\hline Degree of Customer Integration & Up to layout and Design Level \\
\hline Logistics and Supply Chain & $\begin{array}{l}\text { Close Cooperation with suppliers, Factory Network, } \\
\text { Factories in different regions producing local housing } \\
\text { types }\end{array}$ \\
\hline Production Systems & $\begin{array}{l}\text { Production Flow System, Conveyor Belt, Degree of } \\
\text { Factory Production }\end{array}$ \\
\hline On-Site Assembly & about 1 month \\
\hline Customer Relationship & 30 years warranty, Renovation Service (FamiS), \\
\hline
\end{tabular}


Table 3: Summary of Concepts and facts of Sekisui Heim.

Source: Site visits in Japan in 2009, website of Sekisui Heim *

Sekisui Heim breaks down a unique family house into ten to fifteen units, each being an individual module, and each fabricated within the factory up to $85 \%$ completion. Within those units, a multitude of other three-dimensional subsystems from various suppliers with a high degree of prefabrication (e.g. bath and kitchen modules), are integrated in production line based factories. In Japan, this production method has been and further developed and used since nearly half a century ago, and shows many analogies to automotive production. For instance, a continuous production line becomes possible through the introduction of a three-dimensional steel frame being used as a "chassis". This "chassis" support structure is processed with a speed of 1,4 metres per minute, passing more than 45 workstations on a conveyor belt with a length of approximately 400 metres. During this process, it will be equipped with modules, components and subsystems. The "chassis" is finished sequentially in 3 dimensions with components either being supplied just-in-time, or have been produced in parallel processes on different floors (e.g. wall panels). Main concepts and important facts are summarized in Table 3. The following describes and analyses those concepts and parameters.

\section{Design for Industrialized and Automated Customization}

The product structure and its management along the whole life cycle (Lindemann, et al., 2006) is the most crucial and most complex issue in the process chain, in customized prefabrication of individual buildings. The structure has to be developed in respect of the needs of automated production and extended customer integration. Sekisui Heim has already realized this at the beginnings of large scale prefabrication in the 1960's and developed specific fabrication oriented designs and product structures. (Figure 3)

- Hierarchical Decomposition: The hierarchically structured component kit of Sekisui is based on the combination of steel frame units (Unit Method), in order to achieve the desired arrangement of a house. In general, ten to fifteen units were combined to a complete house. The steel frame units are used as "chassis", streaming through the factory and being finished on specially designed production lines from all sides. Similar to a "chassis" in the car industry, the steel frame unit later also serves as the bearing structure. The technical infill like installations, cables and pipes can be seen as sub-components being attached or mounted to the "chassis" just-in-time.

\footnotetext{
* http://www.sekisui.co.jp/ [Accessed: 05 September 2011]
} 
- Open Engineering System: OES means that open component system kits have the ability to be further developed or transformed into new product models or product lines by a company's system designer or engineer (Cormier, et al., 2008). About ten new housing models and about 400 modifications and improvements of existing solutions are introduced annually by the Japanese company Sekisui Heim (Furuse, et al., 2006), making it necessary that the component systems are based on OES principles.

\section{Strategies of Customer Integration}

The design of the configuration process plays a crucial role in any customization strategy, as it links the knowledge about the customer and his preferences to product structure, subsequent fabrication and delivery process. Generally, we can distinguish between on-line and off-line configuration. The on-line configuration is a tool, directly used by the customer, whereas the off-line configuration process is guided and finally performed by a company member, according to customer demands (Lindemann, et al., 2006). As buildings comprise complex products, so far, major Japanese prefab house builders use the off-line configuration method.

- Regional Relation Design: Sekisui Heim offers various types of houses and many of them fit to a specific cultural or climatic region within Japan. In order to get closer to the customers, regionally based model parks have been established in strategically important areas, as well. Accordingly, factories are placed in various areas and produce houses according to the demands of the surrounding area. Nevertheless, those strategically placed factories are integrated into greater, nationwide production clusters and logistical structures.

- Customer Co-Creation: Most Japanese prefab companies hold research and development centres being open to customers. The majority of the $R \& D$ centres accommodate showrooms and/ or sample living areas where customers can choose components, furnishing or configurations. Additionally, customers can take part in certain tests regarding ergonomics and preferences in order to finally co-design the house in an interactive process. Clients are free to choose the degree of customer integration, always determining the price. Continuous process improvements are aimed at lowering cost impacts of a gradual increase of individualization.

\section{Supply Chain Management}

Innovative strategies for logistics determine the efficiency of the resource flow. Important aspects of successful value creation concern the control of the structures which bring resources to the company's value creation system, as well as the resource-circulation within the company's production processes.. Just-in-time and just-in-sequence industrialized production lower input resources and inventory. Advanced Building Information Modelling (BIM) is a precondition for the successful use of tools like Sekisui Heim's "HAPPS” (Heim Automated Parts Pickup System). Today, Sekisui Heim's BIM-System allows a translation up to 95\% of CADdata and further user-input data into logistics, production and assembly information. Further 
BIM-data is used to schedule and manage maintenance, upgrade and remanufacturing during the building's utilization phase. The components and materials are supplied from suppliers and from the warehouse just-in-time and just-in-sequence to a small "preparation" area right next to the production line so that no further transportation to the production line is needed (Figure 4).

- Automated Component Selection: The transition of Sekisui Heim into a highly productive company was initially enabled by its advanced IT-based ERP-System called HAPPS. As explained above, all houses are made of ten to fifteen steel frame units, all finished individually according to customer demands. This means that each unit, prefabricated in the factory, is different. Therefore, it is a complex process to select and pick-up about 30,000 components correctly for each house, out of about 300,000 available components creating the solution space, and feed them to the production line just-in-sequence (Furuse, et al., 2006).

- Automated Task and Production Scheduling: HAPPS is a parameter based system supporting the whole workflow: configuration, planning, receipt of order, logistics, fabrication and delivery. It helps to generate parts, component structures and parts lists from CAD floor plans (Furuse, et al., 2006). Based on the information generated from the CAD models, logistic and production processes are controlled almost automatically.

\section{Prefabrication and Production Systems}

Both the factory organization of Sekisui and Toyota are based on an assembly line production, where the moving steel frame units are customized according to floor plans, functionality, technical infills and the finishing, demanded by an individual customer. Sub-components are fabricated in parallel processes on various floors. Sekisui Heim achieves up to 80\% factory prefabrication, whereas Toyota Home reaches up to 85\%. A factory of Sekisui Heim has a daily capacity of approximately 150 steel frame units, which is equal to ten to fifteen houses, on the 400 meter-production-line.

- Automated Steel Frame Production: One of the basic features is the automated assembling and welding station. Ceiling elements, flooring elements and columns are fed into this station, followed by automatic welding into a frame, which is used as chassis and bearing structure during the further completion process on the production line. (Figure 5)

- Production Flow System: After the automated welding process, the steel frame chassis is streaming through the factory from work step to work step, until it will be finished with all installations (Figures 6). The factories of Sekisui and Toyota have gates on both sides of the assembly lines in order to receive material, parts, components and prefabricated bath or kitchen modules, required for the customized production of individual units. All of them arrive just-in-time and just-in-sequence by cooperating suppliers (Figure 7).

- Pre-Installation: The pre-installation of furniture and cables is an important part of the production strategy of Sekisui and Toyota. The higher the degree of the technical 
installation, the more efficient is the prefabrication. The factory environment is the perfect place for a fast and highly qualified installation of technical infrastructure, further components and sub-systems. The units are processed and finished 3-dimensionally from various sides.

- 0-Waste Factories: In contrast to conventional construction, a minimum of waste was generated throughout the process. Both Sekisui and Toyota aimed at zero-waste factories. This could be achieved with the supply of modules fitting into the product structure without further processing or cut-off waste. Another step to reach the target of zero wastage is the fastidiously sorting of material waste for reuse and recycling (Figure 8). In contrast to conventional production, the industrialized production is highly sophisticated in matters of resource circulation controlling. (Linner and Bock, 2010)

- Quality Oriented Production: Additionally, to quality controls performed by robots and highly trained and qualified staff, the quality is being inspected rigorously after each production step (Figure 9). Every company has developed quality checklists with 200 to 300 different items for each house, in order to reach an early detection of mistakes and save time and cost. Sekisui Heim's aim was to design the production procedure in a way which would handover a $100 \%$ error-free product in order to enhance the companies' reliability.

\section{Rapid On-Site Deployment}

At the last workstation within the factory, the finished modules are prepared for transport (Figure 10). Completed units are delivered on-site just-in-time and just-in-sequence by the companies' transport groups. The finished steel frame units and the prefabricated roof modules were assembled within one day (Figure 11). This means that the house becomes water proof and draughtproof immediately and construction failures and quality losses are thus reduced to a minimum. Within the protected house, specially trained assembly workers (neither Sekisui nor Toyota employs unskilled low cost workers complete house and installation in less than one month. After the assembly of units within one day, minor interior works and outside facilities are completed within a month.

\section{Life Cycle Management and Customer Relationship}

Attracting and retaining clients is essential for the success of any customization oriented strategy. Through the customization process, the companies receive detailed information about the customer in order to establish a strong relationship. (Piller, 2006). In the phase were a house is used, the knowledge about the customer and the delivered product can be used for efficient long-term maintenance (Linner and Bock, 2009). Moreover, the established relationship to the customer could be used for after sales-services and additional life-cycle oriented value chains.

- Handover: The handover of a house from Sekisui or Toyota is designed as an experience and is accompanied by the typical Japanese service attitude. In most cases, the move to the 
new home is performed or at least supported by the companies with none or just a few extra cost. When the house is handed over, the customers also receives a guiding handbook/ manual for the new home.

- Quality certificates and warranty: In order to prove the performance, quality and durability of the house and its sub-systems, the customer receives quality and warranty certificates during the handover of the house. As all individual houses have been fabricated in a highly controlled factory environment, and all pre-production models have absolved rigorous quality tests similar to the automotive industry, a high performance concerning durability and earthquake resistance can be guaranteed.

- Regular Inspection and long-term Maintenance: Toyota gives a warranty of 60 years on basic structure, facade, walls and roof, 30 years on all other elements and five years on frequently used elements as floors. During that time, regular inspections by specially trained maintenance staff ensure that damages are repaired and claims are avoided proactively. Additionally, the customers can choose among different long-term maintenance packages.

\section{Service Innovation: Bundling of Buildings with Services}

Nowadays, buildings are not only related to their physical existence but they become subject to services related to them. Services can also be used to customize products and create individual and exceptional experiences (Gilmore and Pine, 2000). Japanese companies increasingly extend their performance focusing on "services" related to the building's utilization phase. The Japanese prefabrication company Misawa Homes was the first company which introduced a "Home Guarantee System" (1962) and a "After Sales and Maintenance Services System" (1972). All other major prefabrication companies followed this strategy during the 1970's. By establishing service systems, the companies can use the prefabricated buildings' inherent modularity for upgrades, renovation, rearrangement and re-customization services (Bock, et al., 2009). Furthermore, they can offer extraordinary warranty and maintenance services due to the detailed plans and the quality achieved by factory production. Further, customized energy solutions and personal assistance technologies supporting daily life, health and handicapped or aged people (Linner, et al., 2011) are emerging building performance fields, which allow prefabrication companies to use and multiply the tremendous knowledge about the customer, gathered during configuration or rearrangement procedures.

- Upgrade Services: The so-called "Stock Refurbishing Business" of Sekisui exemplarily illustrates the service strategy developed by all major Japanese prefabrication companies. Based on detailed plans and data about the delivered housing products, laid down in BIM, buildings are continuously evaluated. Information about components which should be inspected or changed are generated and reported automatically, via a custom software system and then forwarded to the company staff. The company actively manages the information about delivered products and continuously offers upgrades of interior and exterior design and finishing to the customer. 
- Renovation and Reorganization Services: Both Sekisui and Toyota offer the option to replace or add units due to changes in matters of lifestyle or household size and demands. Nevertheless, reorganization could still be simplified and the systems' modularity, standardization and joining methods offer great potentials for continuous rearrangement services. Those services could take up and carry on the intense customer relation, established through the initial customization process for additional and continuous value creation.

- Customizable Energy Platforms: In 2008, Sekisui Heim started to work with the authors of this chapter on an idea of a customizable, pre-fabricated and partly self-sustaining energy and resource platform, situated beneath a modular home, a so-called "Mainboard", inspired by the principle of computing, which accommodates and electronically controls all water instalments and energy components required for a household. The system is designed in a manner that allows multiple "Mainboard" platforms interacting between each other, in order to form a synergetic relationship between a "Mainboard" cluster and its individual components. Those platforms can be customized as well as re-arranged allowing for continuous services through Sekisui Heim and cooperating suppliers.

- Personal Assistance Technologies: The Toyota PAPI Dream House (Shimizu, 2005), designed and prefabricated based on Toyota Home's cubicle space frames, was co-designed by Ken Sakamura, Professor for Ubiquitous Computing at the University of Tokyo. Courtyard, entrance, kitchen, bathroom, sleeping room and all other rooms have been integrated with sensors, actuators and assistance technologies in order to support the inhabitants. The house is a "concept house” showing Toyota Home's vision of the future house. Microsystems have the ability to facilitate household related services and thus help prefabrication companies to extend their business into the delivery of household related physical and digital services. Further, Daiwa House cooperates with companies as Cyberdyne (HAL) and Toto (Intelligent Heath Toilet) to develop assistance technologies and advanced health care service systems which can be connected to the prefabricated buildings. (Linner and Bock, 2010)

- Reverse Logistics and Re-Customization: All buildings of Sekisui Heim can be accepted as trade-ins for a new Sekisui Heim building. Therefore, the deconstruction process and remanufacturing process have been designed as a modified reversed version of the production and assembly process. For deconstruction, joints between steel frame units are initially eased, and the house is then transported to a special dismantling factory unit by unit, where the outdated sub-components are dismantled and brought into advanced re-use cycles (Sekisui Heim, 2009). For customized and user-integrating prefabrication, the bare steel frame units are inspected and subsequently fed into the production process again.

In summary, the presented service strategies give a hint in which direction the evolution of large-scale industrialized customization in the Japanese building industry advances. The focus shifts on "Service Design" related to the building's life cycle. The traditional distinction between "hard" physical buildings and "soft" household/ owner's life-related services, will be 
overcome in favour of the creation of advanced product-service systems. This extension of the operational scope, moreover, gives Japanese prefabrication companies the chance to make recurring use of configuration data and built up customer relationships.

\section{Importance of Service Design for future Housing}

The findings presented above show that Japans prefabrication industry rather behaves and develops like a "production industry" than a "construction industry". Similar to many other high-tech industries, Japan's prefabrication industry incorporates latest technologies and combines automation, products and services into complex value-capturing systems.

Besides the possibility to customise the building to individual needs (which is also a kind of service), Sekisui Heim's buildings distinguish themselves from conventionally built buildings through services that accompany the physical product. Currently, handover services, warranty and long-term maintenance services, comprise standard services accompanying any building. As Sekisui Heim charges only a very small amount for those services, their main business goal is to attract the customers. New services as renovation and reorganization services, reverse logistics and re-customization are currently start-ups that cannot yet be quantified. However, it can be expected that those services not only lower the adoption barrier but can also be used to build up continuous revenue streams.

Interestingly, all mentioned service models that Sekisui Heim strives for, are directly linked to the modular and industrial production of buildings. The celebration of the handover accompanied by a manual, illustrates that the house is seen as a product. Warranty and maintenance can only be guaranteed for such a long time because the company has fabricated them under high-quality standards within the factory. Upgrade and renovation services are closely related to the modular design of the buildings by the fact that the company holds the production and customer data generated through customization and production phase. Finally, Sekisui Heim, being part of Sekisui Chemical, is a huge and reliable company which is likely to survive the life cycle period of each of the delivered buildings. Thus, large scale industrialization, as in the case of Sekisui Heim, builds a solid basis for bundling life cycle oriented services to buildings.

The linking of services to products, which Sekisui Home and other Japanese prefabrication companies increasingly focus on, becomes more interesting when concerning general developments. More and more business and service concepts aim at creating the basis for product-service-systems (Sakao and Lindahl, 2009) based on micro system technology, which is integrated into objects and environments. It is necessary to consider especially the expansion of ICT in the field of health and the development towards eHealth (Jähn and Nagel, 2004) (Telemonitoring, Telecare, Teletherapy). Primarily, the demographic change, by which Japan will be particularly affected, will necessitate service technologies that are inbuilt in living environments (Wichert and Eberhardt, 2011). In fact, at the moment, many product service systems do not yet aim at custodial or medical services but at services of the field of prevention, 
fitness and wellness. Still, this can be seen as an intermediate stage towards integrating telemedical services and services that aim at teleconsultation into the living environment. A lot of the services can be provided digitally, and even physically performed services can be supervised digitally, in order to be carried out in a more efficient way and in high quality. Furthermore, services that accompany products provide the possibility to achieve a high degree of individualization, e.g. of a standard product (Chesbrough, 2011). Due to Sekisui Heim, the control of the life cycle and accompanied services for the upkeep of functionality of the building via Computer Aided Facility Management (May, 2006), is basically forestalled. Objects in the living environment that are more and more prevalently equipped with micro system technology, form an ideal interface for initializing these services (Weber, et al., 2005). Besides their content, a new aspect of the services today is the possibility to create modular service packages (Meier and Piller, 2011) from the entirety of services that can be adapted to the individual case of need (Service-Bundling). In general, services concerning the household can be divided into the following categories:

1. Classic services in the household for supporting activities of daily life (washing, laundry)

2. Security Services (theft prevention, fire protection)

3. Care Service, Emergency Service

4. Services in the field of Ageing and Care

5. Maintenance Services

6. Services in the field of fitness and health (physiotherapists, doctors, fitness instructors)

7. Services for supply and mobility

For example, furniture systems have been equipped with sensors and particularly aim at service adoption in categories 4 and 6 . A basis for services on the other categories can be provided by integrated micro system technology and a data platform (Larson, et al., 2004; Linner, et al., 2011). With the assistance of micro system technology and data platforms, the efficiency of the provision of these services can be enhanced enormously. As a continuative interpretation of the results of Behrens (et al., 2010), the initializing of services can principally happen in three different ways:

- Manual call of the services (television, remote, pad)

- Autonomous or partly autonomous initiated by sensors (motion sensors, monitoring of vital signs etc.)

- Initiating based on interpretation algorithms and fusion of information from different sensor systems and sub-systems (e.g. Ambient Intelligence)

Microsystems and data collection platforms can increasingly be established in the living environment. In terms of the imaginable services, this field is not yet fully developed, providing hence the possibility of novel value creation models. The Japanese prefabrication companies have identified this correlation and will probably increasingly develop services focusing on living, in order to set themselves apart from their competitors. Therefore, based on the proposed case study it can be recommended that any prefabrication project that aims at large-scale 
production has to consider and integrate each of the following parameters in order to be successful:

- The socio-technical culture in the construction society

- The customer integration in the whole process in a transparent and understandable way

- The impact of the modular structure on customer choice, production and service

- The latest production technology and supply chain management concepts

- The digital chain for all partners and phases

- The life cycle, household and health related service in the business model of prefabrication

- The equipment of buildings with as much micro-systems technology as possible in order to support service provision

\section{Conclusion}

In contrast to many examples of prefabrication published so far, the Japanese prefabrication industry is currently the only one which operates in large scale in terms of production volumes, and extensively uses flow line-like production and automation. As reviewed literature about the Japanese prefabrication industry did not provide sufficient information about the development process of such a powerful prefabrication industry, the authors have done field surveys and visited R\&D centres, sales and production facilities of all major Japanese prefabrication companies. A case study of one of those companies presented in this paper revealed that Japanese prefabrication industry has recognized the importance of after sales services since the 1970's. Nowadays, on the basis of large scale industrialization, further attempts to shift the focus from delivering products towards "services", related to the building's utilization phase, enhance the companies' customer relation and customer inclusion capabilities. Concepts and parameters relevant to the evolution of large-scale industrialization of the Japanese prefabrication industry have been identified and analyzed. Furthermore, key strategies, processes and technologies deployed in the industry, have been identified and described using Sekisui Heim as an example, as this company has deployed industrialization and automation consequently. It has been outlined that services which accompany the hard physical product before delivery or during the building's life cycle, play an important role. Also, it has been found that most services are closely related and enabled by consequent industrialization (e.g. modularity enables rearrangement services). Finally, the growing importance of services for future housing has been discussed. Although the impact of new services on the sales and production volumes is currently is unknown, the marketing research divisions of Sekisui Heim investigate the customer acceptance of the solution space offered in a six-month cycle, in order to adjust their products and strategies. The results of these investigations are fed back into design development stage and continuously improve the products. During the development of new models and the marketing of existing ones, it is also usual that customers are invited to visit one of the research and development centres, in order to test various parts of the housing systems, using criteria such as usability and accessibility. However, customer needs are not static and have to be served continuously. Sekisui Heim has realized this matter and worked on extending the degree of customer integration into the direction of services, and integrating the 
customer throughout the life cycle phase of the produced house via services. Currently, Sekisui Heim (as well as other Japanese prefabrication companies) gradually extends its' performance focus on "services" related to the building's utilization phase, trying thus to remain in touch with the customer, serving his changing needs. Sekisui Heim thus now no longer only offers long-term maintenance service packages and upgrade services bundled to their housing products, but also allows deconstruction, re-customization and relocation of its prefabricated buildings, and a variety of other service under development in its R\&D centres.

\section{Acknowledgments}

We thank the AUSMIP Consortium (ICI Education Cooperation Program, EU-Japan) and the Professors and Institutions involved in it for supporting the proposed research. Particularly, we thank Prof. S. Matsumura, Prof. T. Yashiro and Dr. Ken Shibata for supporting us with information and assisting on organizing the research trips. Further, we thank Sekisui Heim, Toyota Home, Daiwa House and Sekisui House for granting us access to their factories and research centres. Last but not least, we thank the general management of Sekisui Heim for arranging meetings with system developers, researchers, sales persons and other company staff.

\section{References}

Andersson, R., Eckholm, A., Jonsson, C., Molnar, M., Larsson, R., 2010. ICT and BIM in Japanese Construction Industry. Samhällsbyggaren, [online] June 2010. Available at: http://www.vbyggaren.se/pdf_arkiv/Samhallsbyggaren_6_10.pdf [Accessed 05 September 2011]. pp. 46-51.

Baldwin, C., Clark, K., 2000. Design Rules - The Power of Modularity. Massachusetts: The MIT Press.

Bergdoll, B., Christensen, P., 2008. Home Delivery - Fabricating the modern dwelling. [exhibition catalogue] Basel/ Boston/ Berlin: Birkhäuser.

Bock, T., Linner, T., Lee, S., 2009. Integrated Industrialization Approach for lean On-/ Off-site Building Production and Resource Circulation, 7th World Conference on Sustainable Manufacturing. Madras, India 2-4 December 2009, Madras, Prof. M. S. Ananth.

Bock, T., Linner, T., 2010. Off-site Industrialization - Process and Production Technologies Towards Customised Automation and Robotics in Prefabrication of Concrete Elements. In: Girmscheid, G., Scheublin, F. eds. 2010. New Perspective in Industrialization in Construction A State-of-the-Art Report. Zürich: Eigenverlag des IBB (Institut für Bauplanung und Baubetrieb) an der ETH Zürich. Ch. III, F. 
Chesbrough, H., 2011. Open Services Innovation. Stadt: San Francisco: Jossey-Bass, A Wiley Imprint.

Forza, C., Salvador, F., 2007. Product Information Management for Mass Customization. New York: Palgrave Macmillian.

Cormier, P., Olewnik, A., Kemper, L., 2008. An Approach to Quantifying Design Flexibility for Mass Customization. Proceedings of the ASME 2008 International Design Engineering Technical Conferences \& Computers and Information in Engineering Conference. New York, USA, 3-6 August 2008, New York: IDETC/CIE.

Daiwa House: http://www.daiwahouse.co.jp [Accessed 05 September 2011]

Daiwa House, research visit in 2008

Fujimoto, T., 1999. The Evolution of a Manufacturing System at Toyota. Oxford/ New York: Oxford University Press.

Furuse, J., Katano, M., 2006. Structuring of Sekisui Heim automated parts pickup system (HAPPS) to process individual floor plans, International Symposium on Automation and Robotics in Construction (ISARC). Tokyo, Japan, 3-5 Oktober 2006, Tokyo, Symposium Committee.

Gilmore, J., Pine, B., 2000. Markets of One. Creating Customer-Unique Value through Mass Costumization. Boston: Harvard Business School Publishing.

Girmscheid, G., Scheublin, F., 2010. New Perspective in Industrialization in Construction - A State-of-the-Art Report. Zürich: ETH Zürich and CIB.

Girmscheid, G., 2010. Off-site Production methods - Precast Plant Production. In: Girmscheid, G., Scheublin, F. eds. 2010. New Perspective in Industrialization in Construction - A State-ofthe-Art Report. Zürich: Eigenverlag des IBB (Institut für Bauplanung und Baubetrieb) an der ETH Zürich. Ch. III, G.

Habraken, J. ed., 2000. The Structure of the Ordinary - Form and Control in the Built Environment. Cambridge: The MIT Press.

Jähn, K., Nagel, E., 2004. eHealth. Berlin: Springer-Verlag.

Johnson, W., 2008. Lessons from Japan: A comparative study of the market drivers for prefabrication in Japanese and UK private housing development. London: Master Thesis at University College London.

Kendall, S., Teicher, J., 2000. Residential Open Building. London: E \& FN Spon for International Council for Building Research (CIB). 
Larson, K., Intille, S., McLeish, TJ., Beaudin, J., Williams, RE., 2004. Open Source Building Reinventing Places of Living. BT Technology Journal, vol. 22(4), 187-200

Lindemann, U., Reichwald, R., Piller, F., 2006. Individualized Products. Berlin: SpringerVerlag.

Linner, T., 2007. Prefabrication Strategies in Japan. Munich: Master Thesis.

Linner, T., Bock, T., 2009. Smart Customization in Architecture: Towards Mass Customization of Intelligent Buildings, Conference on Mass Customization, Personalization and Co-creation. Helsinki, Finnland, 4-8 October 2009, Helsinki, Piller F.

Linner, T., Bock, T., 2010. Enhanced Industrialized Customization Performance by Building Integrated Microsystems, 27th International Symposium on Automation and Robotics in Construction (ISARC). Bratislava, Slowakei, 25-27 June 2010, Bratislava, Josef Gašparík.

Linner, T., Kranz, M., Roalter, L., Bock, T., 2011. Robotic and Ubiquitous Technologies for Welfare Habitat. Journal of Habitat Engineering, Vol. 3, No. 1, pp. 101-110.

Matsumura, S., 2007. Research in prefabrication. [interview and discussion] (personal discussion February 2007).

May M., 2006. IT im Facility Management erfolgreich einsetzen. $2^{\text {nd }}$ ed. Berlin: Springer Verlag.

Meier, R., Piller, T., 2011. Systematisierung von Strategien zur Individualisierung von Dienstleistungen. München: Arbeitsberichte des Lehrstuhls für Allgemeine und Industrielle Betriebswirtschaftslehre an der Technischen Universität München.

Ohno, T., 1988. Toyota Production System - beyond large scale production. Massachusetts: Productivity Press.

Piller, F., 2006. Mass Customization - Ein wettbewerbsstrategisches Konzept im Informationszeitalter. $4^{\text {th }}$ ed. Wiesbaden: Deutscher Universitätsverlag, p. 229.

Sakao, T., Lindahl, M., 2009. Introduction to Product/ Service-System Design. London: Springer-Verag.

Sekisui Heim: http://www.sekisui.co.jp/ [Accessed 05 September 2011]

Sekisui Heim, research visits in 2008, 2009 and 2010

Sekisui House: http://www.sekisuihouse.co.jp/ [Accessed 05 September 2011]

Sekisui House, research visits in 2008 and 2009 
Shimizu, N., 2005. A House of Sustainability: PAPI - Intelligent House in the Age of Ubiquitous Computing. Architecture and Urbanism (AU), Special Issue December 2005.

Behrens, H., Fahl, P., Trage, M., 2010. Standards für wohnungsbegleitende Dienstleistungen im Kontext des demografischen Wandels und der Potenziale der Mikrosystemtechnik - Das Projekt STADIWAMI. In: Tagungsband des 3. Deutschen AAL-Kongresses - Assistenzsysteme im Dienste des Menschen: zuhause und unterwegs. Berlin/ Offenbach: VDE-Verlag.

Toyota Home: http://www.toyotahome.co.jp/ [Accessed 05 September 2011]

Toyota Home, research visits in 2008, 2009 and 2010

Wichert, R., Eberhardt, B., 2011. Ambient Assisted Living. Berlin: Springer-Verlag.

Wimmer, R., 2009. Strategieentwicklung für eine industrielle Serienfertigung ökologischer Passivhäuser, Bericht aus Energie und Umweltforschung. Wien: Bundesministerium für Verkehr, Innovation und Technologie.

Weber, W., Rabaery, J., Aarts, E., 2005. Ambient Intelligence. Berlin: Springer-Verlag.

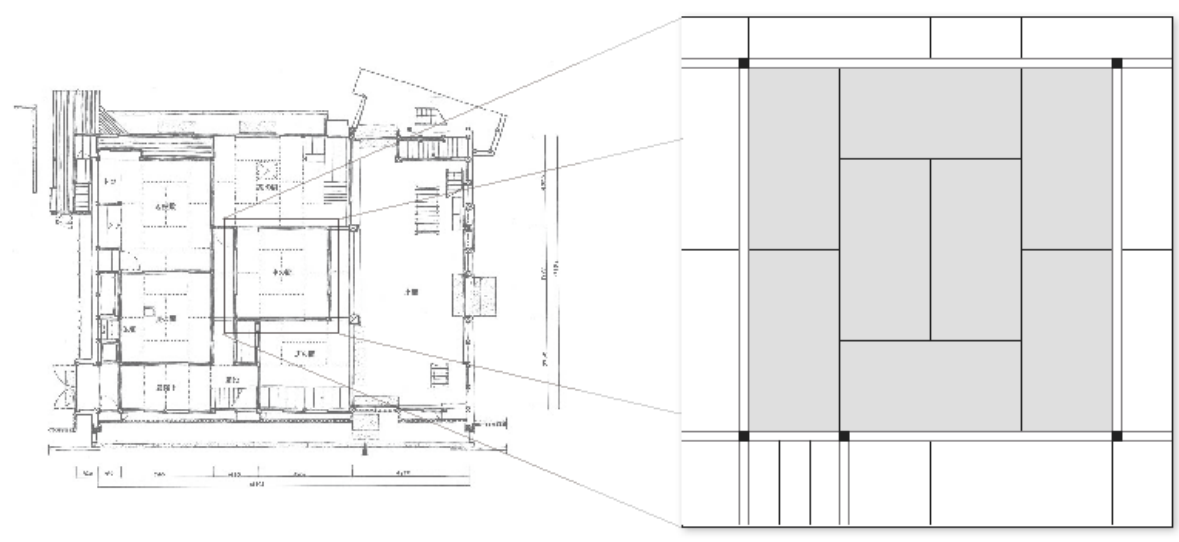

Figure 1: Unique Measurement systems like the Tatami supported standardization and prefabrication. 

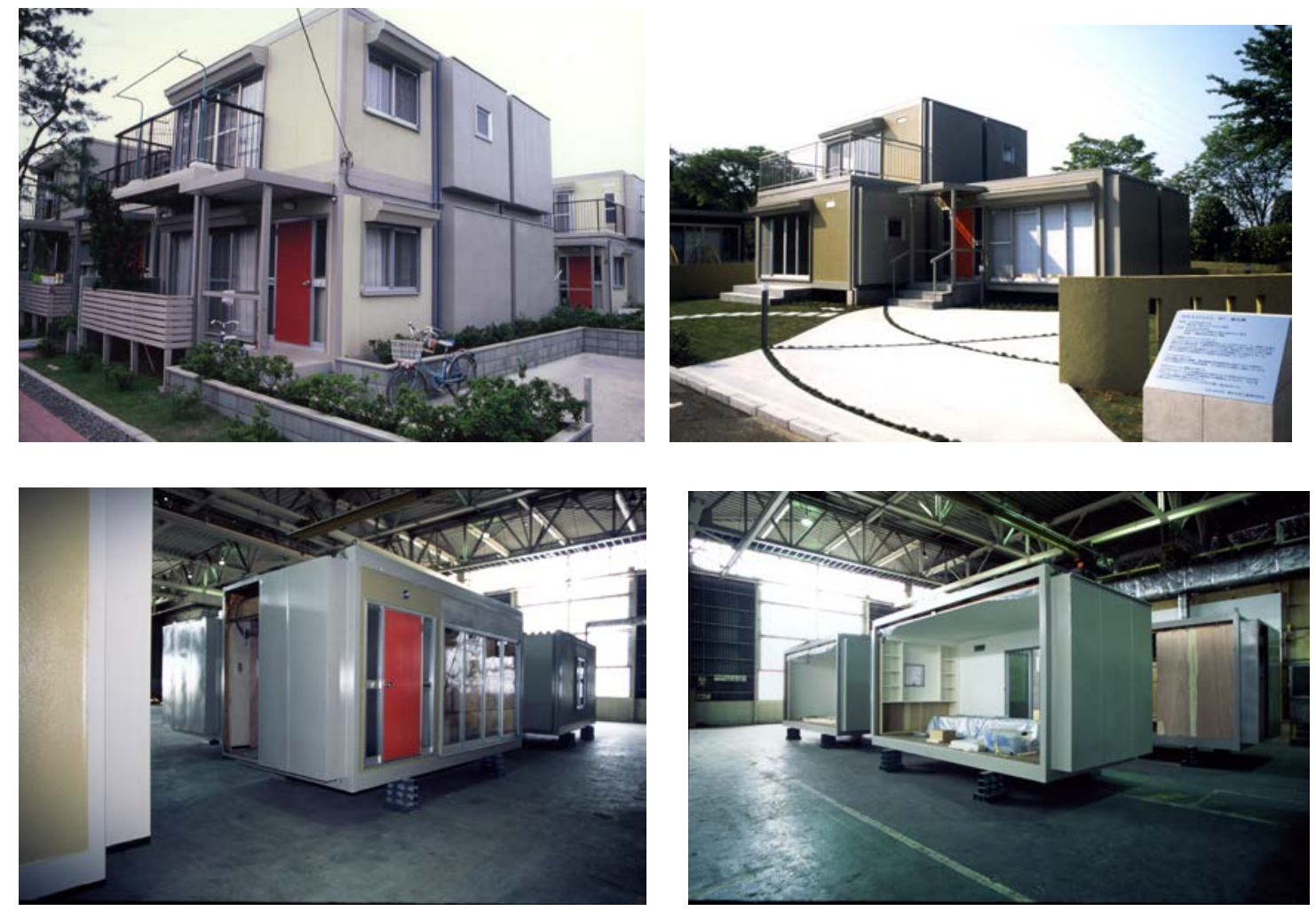

Figure 2: Sekisui Heim's legendary M1 was the first prefabricated housing model which reached an annual production of over 3000 buildings/year over several years. 


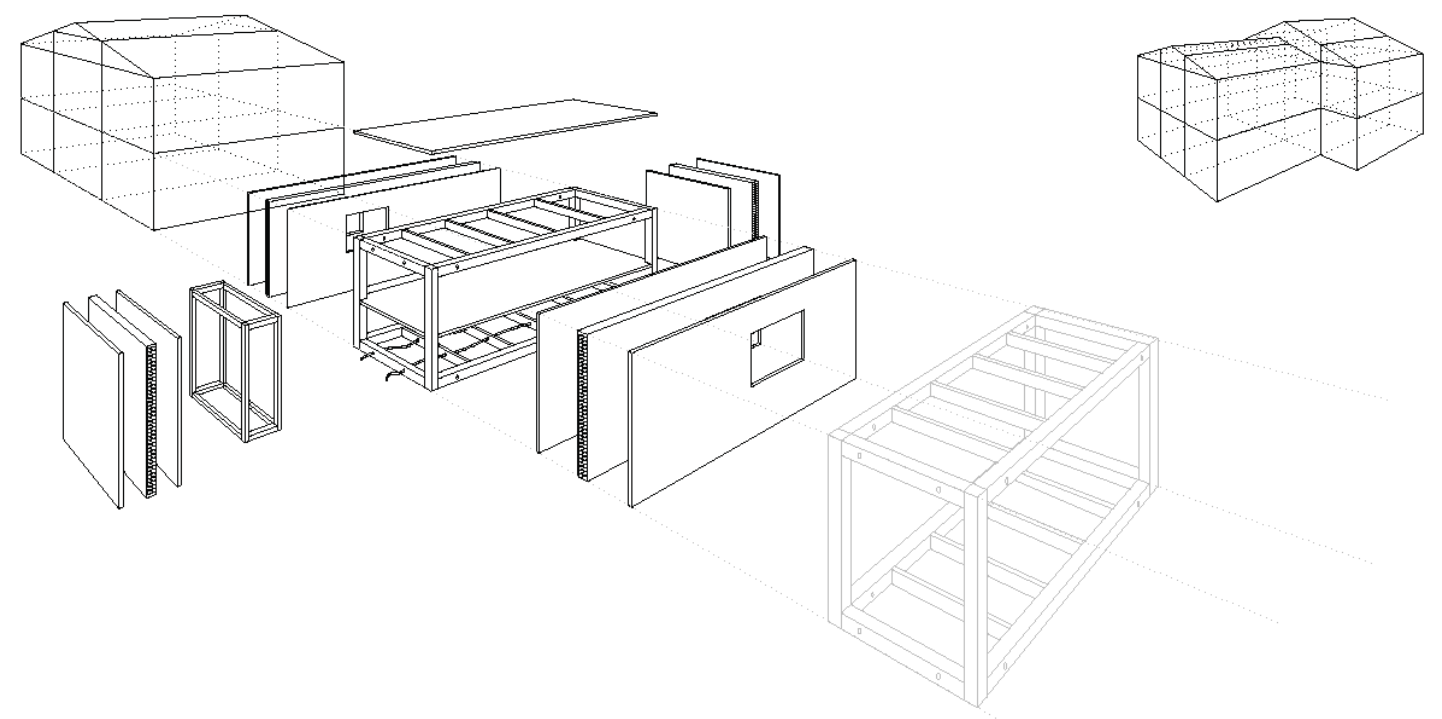

Figure 3: Sekisui Heim's component kit is based on a steel frame chassis being sent onto moving production lines for subsequent completion. An average house consists of 10-15 of those prefabricated units.
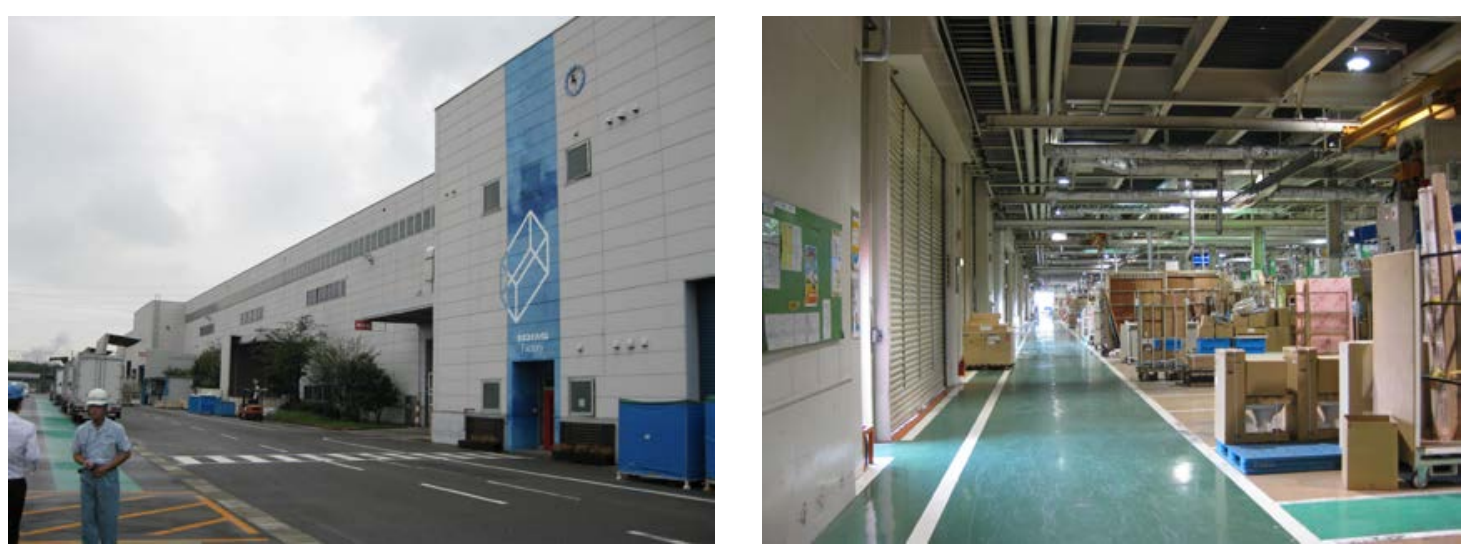

Figure 4: Exterior and Interior view of one of the two supply sides which flank the production line. The components and materials are supplied from the left side just in time and just in sequence to a small "preparation" area - from there it goes directly to the production line on the right side. 


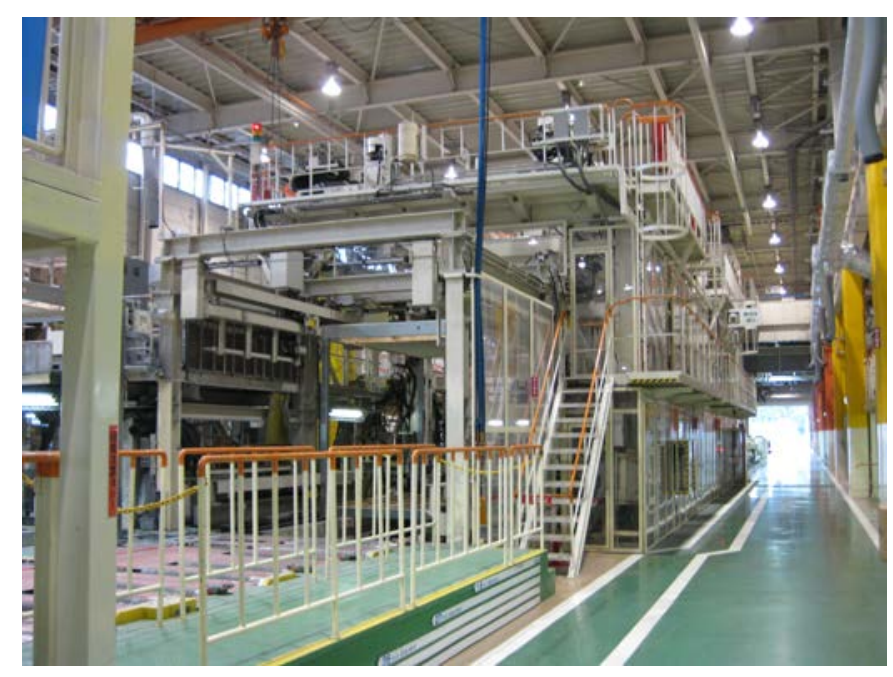

Figure 5: Automated assembly and welding of steel profiles to units.

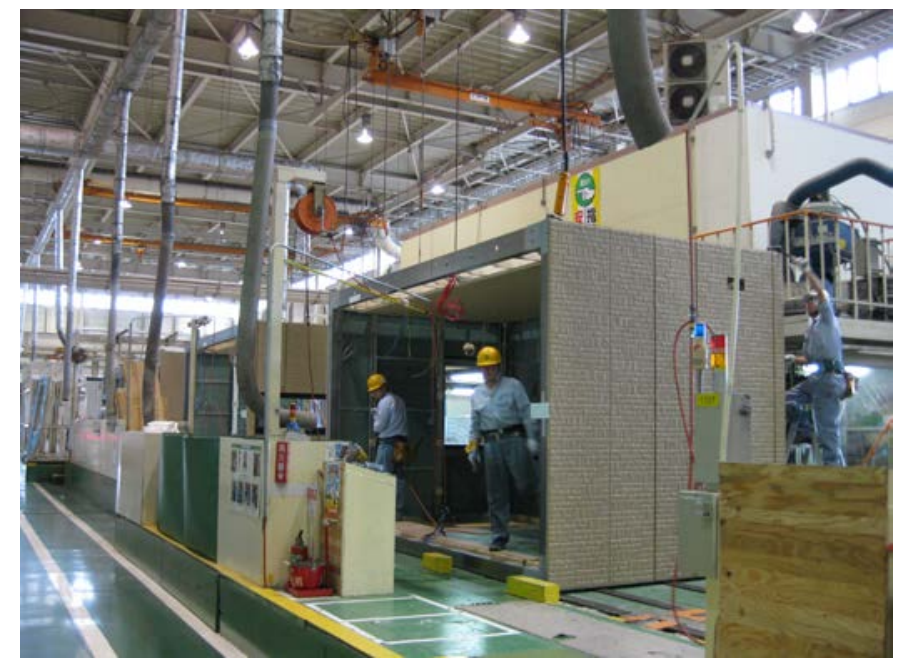

Figure 6: On the 400m production line, the steel frame units ("chassis”) pass several workstations. 


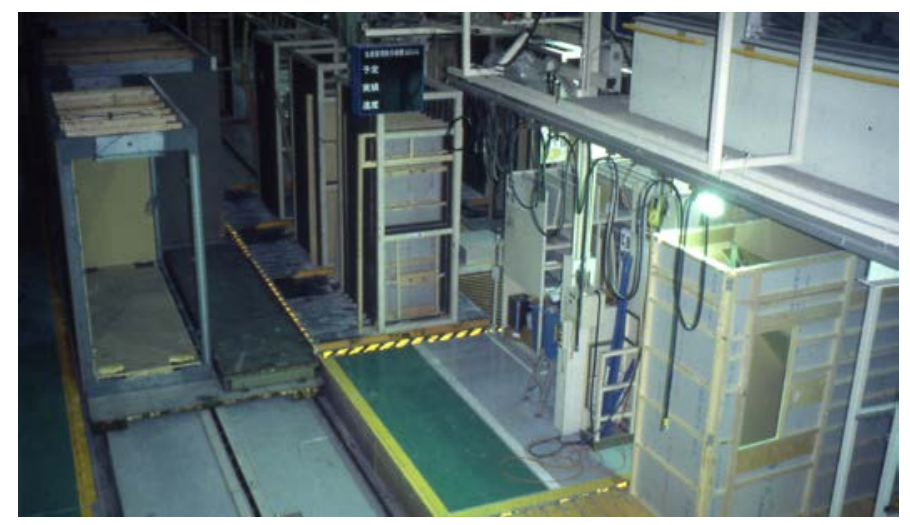

Figure 7: Insertion of prepared elements and by suppliers (e.g. Toto, Inax) prefabricated bath modules into the chassis unit.

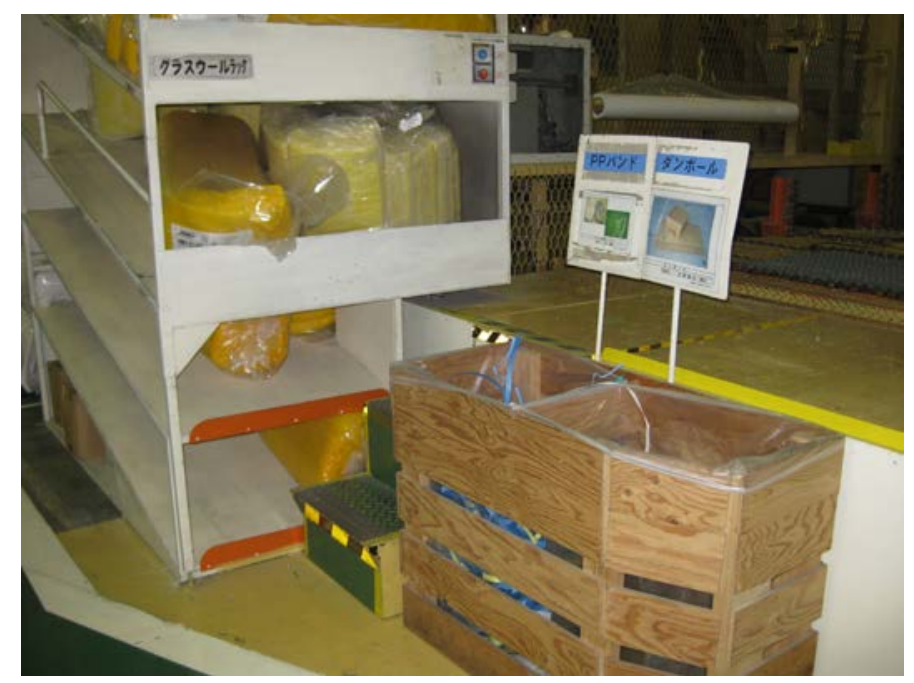

Figure 8: Materials as e.g. insulations are supplied to the factory already in the fitting sizes minimizing cutoff waste. The remaining waste is sorted fastidiously in up to 40 categories. 


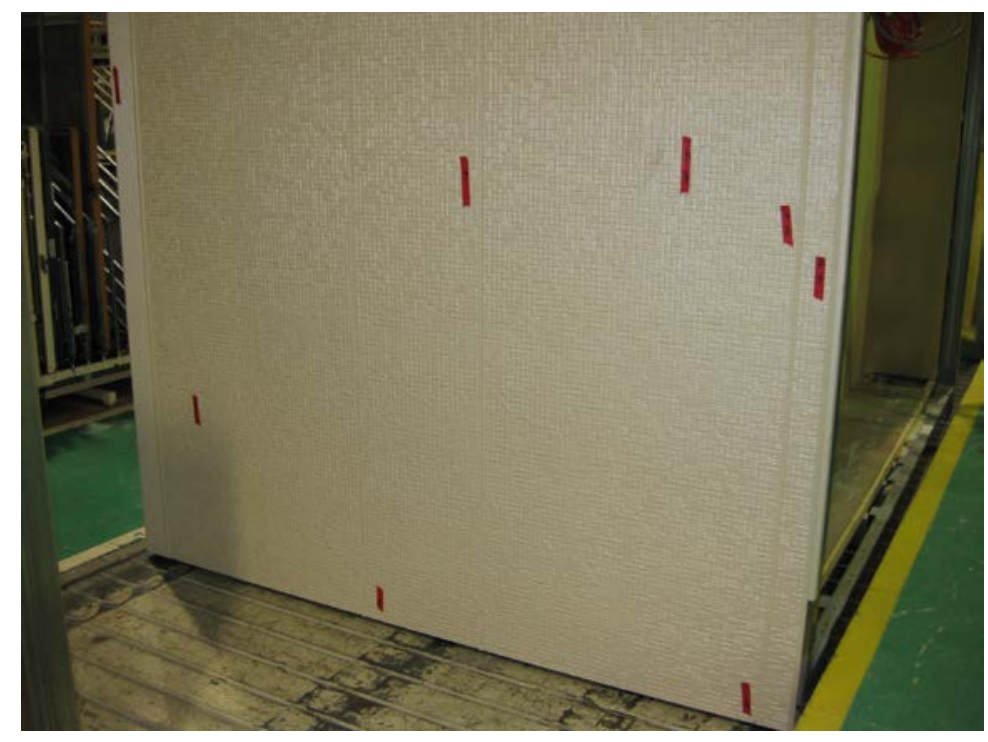

Figure 9: After each station in the production process the units, and attached materials undergo a rigorous quality check.

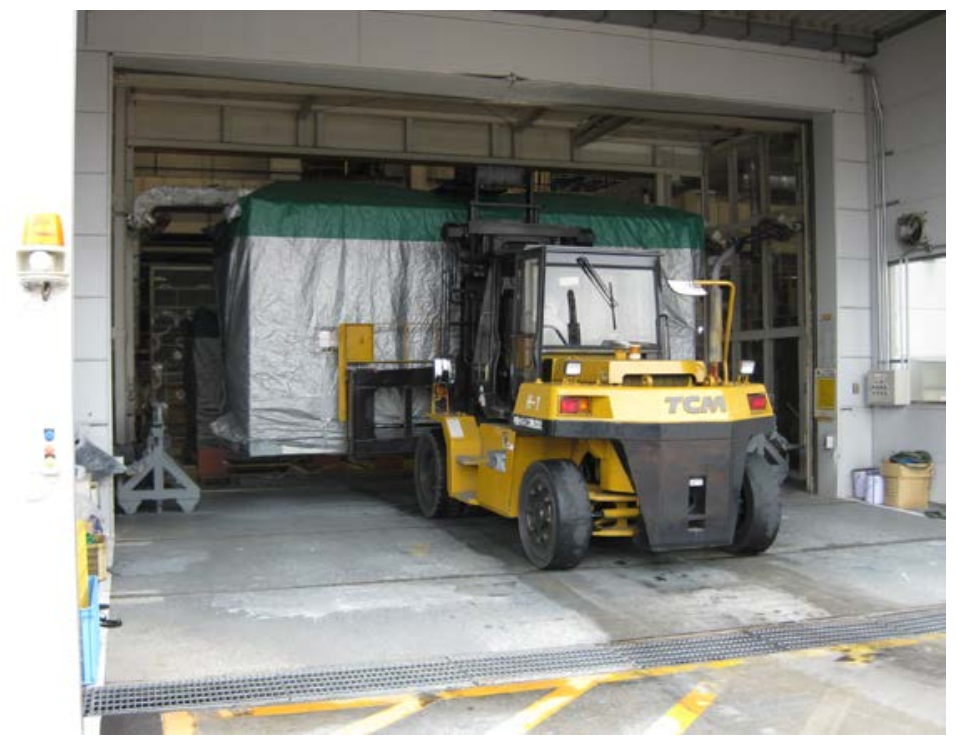

Figure 10: At the last workstation within the factory, the finished modules are prepared for transport. 


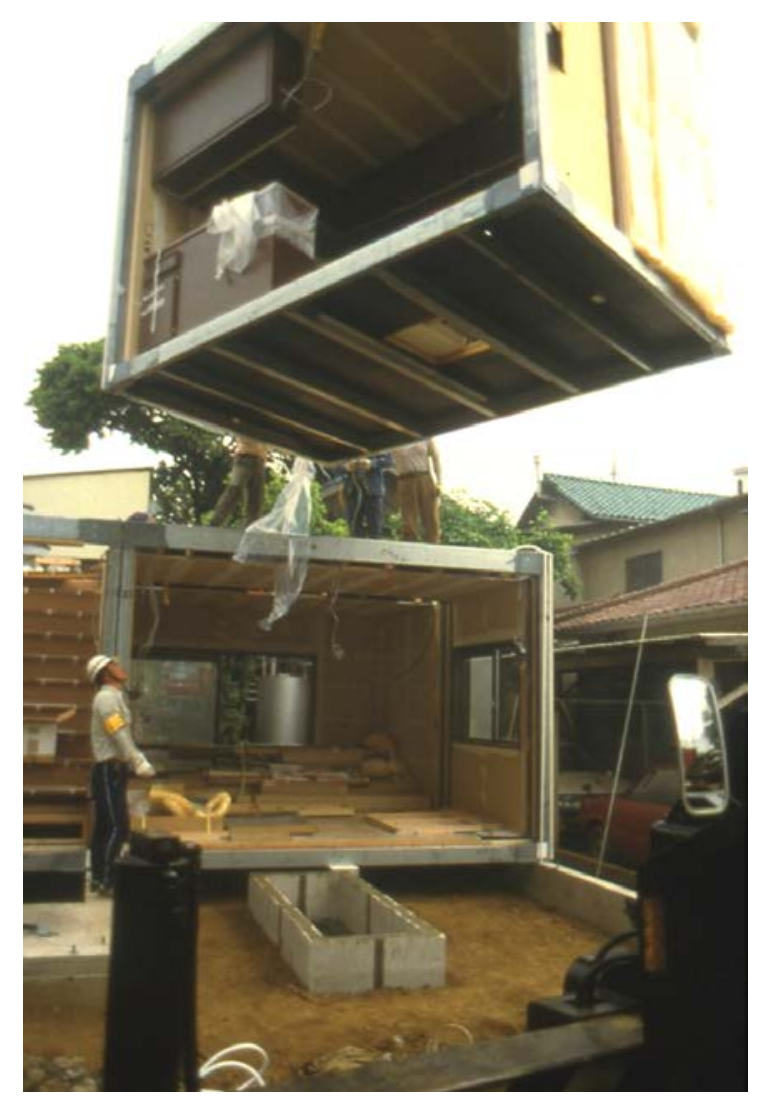

Figure 11: On-Site assembly of $80 \%$ prefabricated House

(C) Emerald Group Publishing Limited 2012

\section{Licensing statement}

Emerald allows authors to deposit their AAM under the Creative Commons Attribution Non-commercial International Licence 4.0 (CC BY-NC 4.0). To reuse the AAM for commercial purposes, permission should be sought by contacting permissions@emeraldinsight.com.

For the sake of clarity, commercial usage would be considered as, but not limited to:

- Copying or downloading AAMs for further distribution for a fee;

- Any use of the AAM in conjunction with advertising;

- $\quad$ Any use of the AAM by for promotional purposes by for-profit organisations;

- Any use that would confer monetary reward, commercial gain or commercial exploitation. 